\title{
6
}

\section{Measurement of Vertical Temperature Profiles in a Stormwater Detention Pond}

\author{
Darryl Dormuth and Kendra Leboldus
}

\subsection{Introduction}

During and subsequent to a rainfall event, stormwater runoff can transport heat from an urban area (which can be significantly warmer than its surrounding region) to a receiving water body, such as a stream, river, lake, or a wetland. Excess heat can affect an aquatic ecosystem in the following ways (Thomann and Mueller, 1987):

- direct lethal effect on sensitive plants or animals;

- indirect long-term effects on the aquatic ecosystem by affecting growth and/or reproduction; and

- indirect effects through changes in species distribution in the ecosystem.

Observations have been made that support the idea that stormwater runoff can contain enough heat energy to warm the water of a receiving body above temperatures that can harm biota living within it (Galli, 1990; Herb et al., 2009; James and Xie, 1999; Kieser et al., 2004; Li and James, 2004; Nelson and Palmer, 2007; Van Buren, 1999; Verspagen, 1995). Consequently many jurisdictions have implemented regulatory guidelines on temperature limits of urban stormwater runoff. For example, in the Stormwater System Design Manual that is produced by the Ontario Ministry of the Environment it is stated (Ontario Ministry of the Environment, 2003, Section 3.3.4.2):

Where temperature is a significant concern it is recommended that the designer consult with the local conservation authority, the federal Department of Fisheries and Oceans (Fisheries and Habitat Management) and the Ontario Ministry of Natural Resources, during the design process.

Dormuth, D. and K. Leboldus. 2011. "Measurement of Vertical Temperature Profiles in a Stormwater Detention Pond." Journal of Water Management Modeling R241-06. doi: 10.14796/JWMM.R241-06. (C) CHI 2011 www.chijournal.org ISSN: 2292-6062 (Formerly in Cognitive Modeling of Urban Water Systems. ISBN: 978-0-9808853-4-7) 
A challenge for municipalities is to predict under what conditions stormwater effluent could violate regulatory limits. If such conditions could be predicted with sufficient accuracy then management practices could be developed to mitigate the adverse impacts on the receiving water bodies. To support this endeavour, several computer models have been developed to evaluate the transport of heat energy in urban stormwater systems (or components within them). Results from these models should be compared to measured values from representative systems to demonstrate that the important processes have been adequately simulated and to establish the validity of these models for this type of problem.

The focus of this chapter is on using a low cost sensor array to measure temperature at different depths throughout a water column in wet detention ponds, i.e. ponds that retain a permanent pool of water between rainfall/runoff events. Wet detention ponds have been used in the management of urban stormwater runoff for several decades and are considered essential components in many stormwater systems. For many of these ponds, the ratio of the water surface area to the pool volume is large enough that the water temperature responds quickly to changes in atmospheric conditions. In particular, these ponds can heat up during summer days and become warmer than nearby natural water bodies.

Van Buren et al. (2000) observed that an on-stream detention pond, in Kingston, Ontario, with an average depth of $1 \mathrm{~m}$ added thermal energy to the creek into which it discharged. They measured the temperatures at the inlet, outlet and at one point in the pond $(1 \mathrm{~m}$ below the waterline, just above the pond bottom) at $20 \mathrm{~min}$ intervals from May to September, 1997. A series of discrete water temperature surveys was also conducted in the pond where temperature was measured at depths of $0.10 \mathrm{~m}, 0.45 \mathrm{~m}$ and $0.90 \mathrm{~m}$ below the water surface, and $0.10 \mathrm{~m}$ above the pond bottom, at nineteen different locations. They found that temperature varied at the different locations and depths. During rainfall/runoff events, the pond had two distinct flow zones in the horizontal plane (Shaw et al., 1997) and temperature differences were observed between these zones. In the advection zone, flow was from the inlet to the outlet (with higher velocities than average) in a direct route and the water temperature was up to $2.0^{\circ} \mathrm{C}$ cooler than water in the recirculation zone, where flow velocities were considerably less than average. Between rainfall/runoff events and under conditions of low flow and calm winds, it was observed that the average temperature at the water surface was $3.6^{\circ} \mathrm{C}$ warmer than at the bottom of the pond (where temperature was monitored continuously). These observations suggest that the assumption of well mixed conditions, i.e. a single representative temperature for water temperature in the pond, needs careful consideration as variations in temperature can exist. 
In a study conducted by Herb et al. (2009), a wet detention pond in Woodbury, Minnesota, was instrumented with a string of thermistors, which collected temperature measurements at seven elevations through a $2.5 \mathrm{~m}$ water column in the pond, from June 3 to August 25, 2005. The observations showed that the vertical temperature gradient in the pond varied during the course of the monitoring season and there could be several degrees centigrade difference in water temperature between the top and bottom of the pond. Temperature measurements were also taken near the inlet and outlet of the pond and it was observed that the overall average outlet temperature was $1.2{ }^{\circ} \mathrm{C}$ higher than the inlet temperature but with significant variations among the rainfall events. Although higher outlet temperatures were observed in some cases, the primary function of the pond is to attenuate peak flow which means that heat energy added to a downstream water body would be over a greater duration than if the pond was not in the system. Therefore, the use of a wet pond to mitigate the thermal impacts from urban runoff on a water body results in a tradeoff between reducing the magnitude of the temperature increase on the water body and lengthening the duration of this increase.

To build upon the work done by Van Buren et al. (2000) and Herb et al. (2009), more monitoring of water temperatures in wet detention ponds is being planned by the authors of this chapter. The main driver for this is to examine the effects of pond bathymetry and the locations of inlets and outlets on the water temperature within and exiting the pond. A better understanding of these relationships could help in the design of wet detention ponds to better mitigate the thermal effects of urban stormwater runoff on water bodies.

It is realized that to build a sufficient database of measurements for this endeavour will require several thermal arrays to measure vertical temperature profiles in the ponds. The thermal sensor array proposed in Section 6.2 was designed to minimize cost while maintaining the ability to collect good quality temperature measurements. This array was tested in a wet detention pond in Regina, Saskatchewan, from September 9 to October 16, 2009, and the results of this evaluation are presented in Section 6.3. Conclusions on the evaluation as well as recommendations for further deployments of the thermal sensor array are provided in Section 6.4.

\subsection{Thermal Sensor Array}

As mentioned in the previous section, one of the research goals at NRCCSIR is to build a database of temperature measurements in stormwater ponds that can be used to validate and improve computer models To achieve 
this, it is desirable to have the capability of deploying multiple arrays in one pond and to keep them in place for several weeks to continuously monitor complete transients of storm events and several diurnal cycles. Based on achieving these goals, the following design objectives for the thermal sensor array were established:

- the ability to be deployed and left unattended in the pond for several weeks;

- the ability to collect temperature measurements at $25 \mathrm{~cm}$ increments (or smaller) through the depth of the pond;

- the ability to collect data with a frequency of at least one measurement every hour and to store at least two weeks of measurements;

- the ability to collect temperature measurements at the water surface;

- a measurement uncertainty of $\pm 0.1^{\circ} \mathrm{C}$ or less; and

- aim for a cost target of $\$ 1000$ or less per string. (All prices are stated in 2009 Canadian dollars.)

The first design concept that was explored was a thermistor string that could be connected to a datalogger. A quote was received from a company for an string of eight thermistors, each spaced $25 \mathrm{~cm}$ apart over $2 \mathrm{~m}$, that was waterproof, had a measurement uncertainty of $\pm 0.1^{\circ} \mathrm{C}$, and could connect to a datalogger. The price for this string was approximately $\$ 2000$. In addition to the cost of the thermistor string, a datalogger with at least eight input channels and power supply was needed and these had to be encased in a waterproof container. The cost of these items came to approximately $\$ 3000$. The option of situating the datalogger on land and running a cable to the thermistor string was considered but it was estimated to cost more, mostly because of the need to secure the site. The total cost of this system came to approximately $\$ 5000$ for one string, which was well over the target cost.

The second design concept was to create a sensor array by attaching a series of integrated thermistor-datalogger (ITD) units onto a pole. The two main drawbacks to this concept (in comparison to the thermistor string) are that these units have a greater measurement uncertainty $\left( \pm 0.2^{\circ} \mathrm{C}\right.$ to $\left.\pm 0.5^{\circ} \mathrm{C}\right)$ and each unit must be separately programmed, synchronized with the others, and accessed in order to acquire the temperature histories. However, as will be shown below, the cost of using ITD units is significantly less than the thermistor string. Another advantage of this concept over the thermistor string is that the units can be arranged at any spacing and easily repositioned, if necessary.

One manufacturer of an ITD unit is Maxim Integrated Products, which produces the iButton (see Figure 6.1). The cost of one unit is approximately 
$\$ 40$, which must be placed into a waterproof case (approximately $\$ 30$ ). A USB connector is required to program and access the data, which is approximately $\$ 30$ and only one is needed for all units. The software to program and access the data with a personal computer is supplied by the manufacturer and is free. Thus, a thermal array with eight units would cost approximately $\$ 590$, which is substantially less the thermistor string.

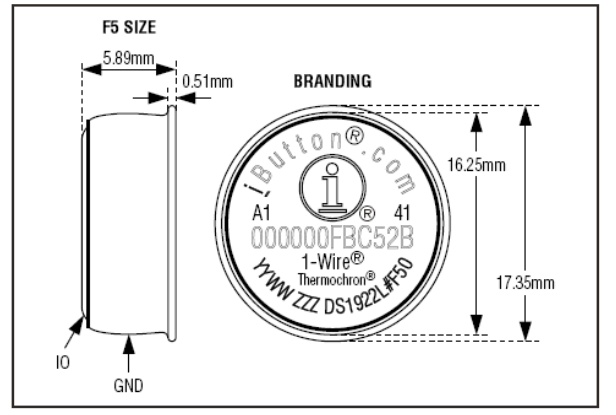

Maxim iButton Temperature Logger DS1922L

- Operating range: -40 to $+85^{\circ} \mathrm{C}$

- Accuracy: $\pm 0.5^{\circ} \mathrm{C}$ from -10 to $+65^{\circ} \mathrm{C}$

- Sampling rate: from 1 second to 273 hours
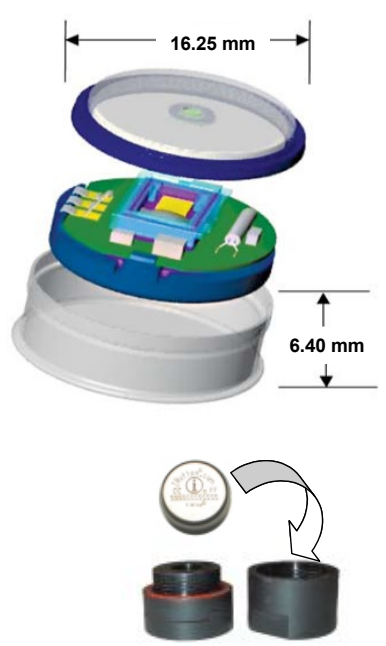

Waterproof capsule

Figure 6.1 Dimensions and specifications for the Maxim DS1922L iButton temperature logger and waterproof capsule (images obtained from www.maxim-ic.com ).

Another ITD is the HOBO TidBit, which is manufactured by Onset It has a better measurement accuracy $\left( \pm 0.2^{\circ} \mathrm{C}\right)$ than the iButton but is more expensive. A waterproof unit costs approximately $\$ 130$ and requires an optical USB reader with software (approximately \$205). Using this product, a thermal array with eight units would cost approximately $\$ 1245$. One feature of this product is that for an additional $\$ 105$, a waterproof shuttle can be purchased, which can be used to download data without connecting the TidBits directly to a computer. This feature will be discussed more in Section 6.4.

It was decided that for the prototype sensor array the iButton units would be used (hereafter denoted as an ITD unit) and to increase the number of the units on the array to twenty (an inter-unit spacing of $10 \mathrm{~cm}$ ) to obtain a finer resolution of the vertical temperature profile for the concept evaluation. An illustration of the prototype sensor array and its enclosure is shown in Figure 6.2 . 


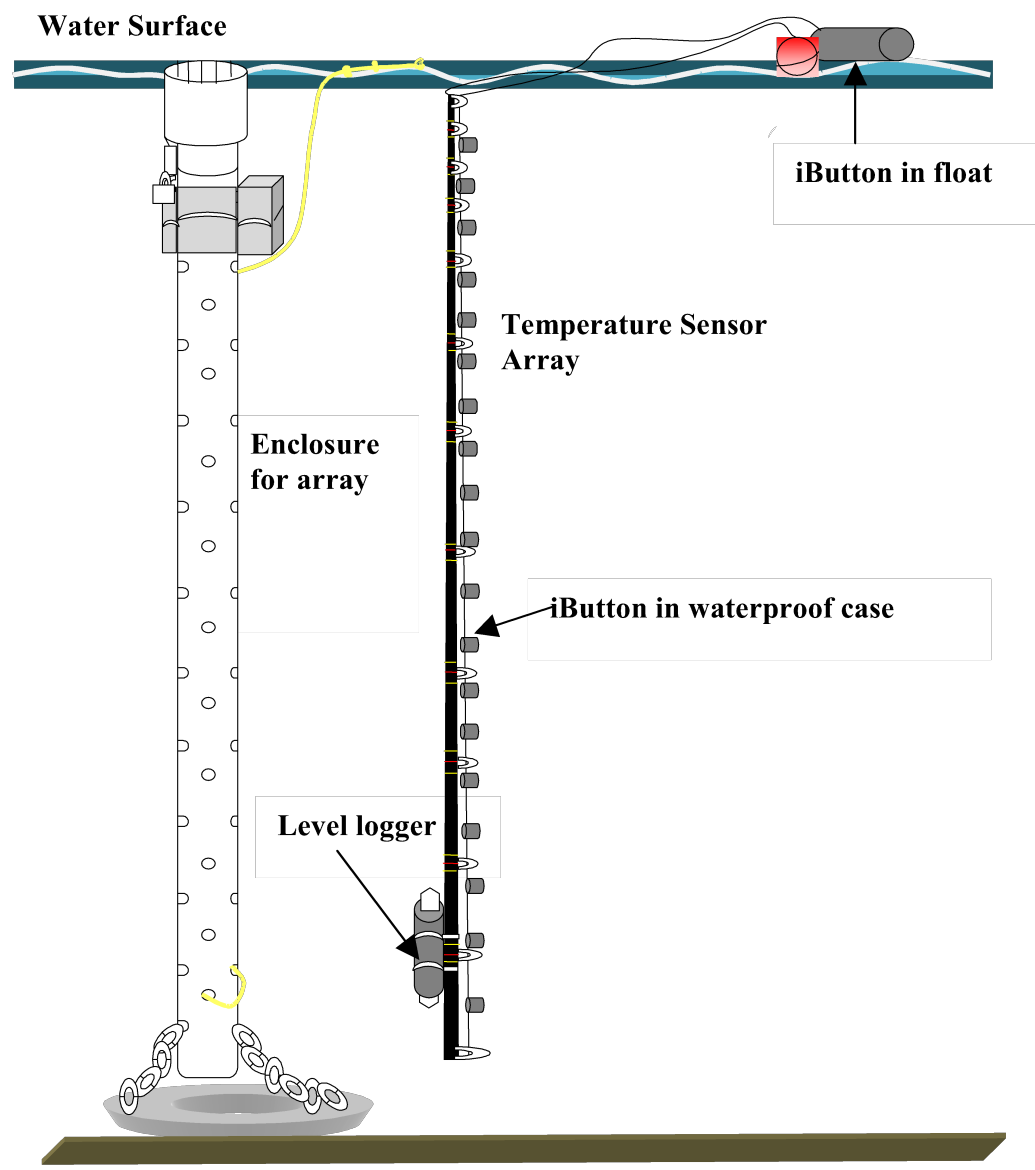

Bottom of Detention Pond

Figure 6.2 Illustration of the thermal array prototype. The enclosure for the array is shown on the left and the array itself, which sits inside the enclosure, is in the middle of the figure.

The thermal sensor array (middle of Figure 6.2) was constructed as follows:

1. A fishing rod that was cut to a length of $2 \mathrm{~m}$ at the handle end. This length corresponded to the depth of the pond in the case study;

2. A metal wire loop was added to the bottom of the rod and secured with electrical tape;

3. A fishing line was threaded through the guides and secured at both ends of the rod; 
4. The ITD units were placed in the waterproof capsules, which were secured to the fishing line at $10 \mathrm{~cm}$ intervals;

5. One ITD (inside its capsule) was placed inside a $15 \mathrm{~cm}$ piece of foam pipe insulation. The insulation was attached to the top of the rod with a $75 \mathrm{~cm}$ piece of fishing line that allowed it to float on the water surface; and

6. A HOBO water level logger was secured in a piece of foam pipe insulation (this did not affect the sensor's performance) and was attached to the rod $10 \mathrm{~cm}$ from the bottom with plastic-coated wire. In case the logger detached from the rod, a separate fishing line was attached to one end of the logger, threaded up through the guides, and tied to a red and white float.

To permit easy retrieval of the sensor to download data, an enclosure was constructed in which it could sit in a fixed position (see left side of Figure 6.2). This enclosure consisted of a poly-vinyl chloride (PVC) pipe that was $7.6 \mathrm{~cm}$ diameter and $2 \mathrm{~m}$ long and had $2 \mathrm{~cm}$ holes drilled throughout its length to permit water flow. For security, an $8 \mathrm{~cm}$ PVC collar was fixed to the top of the pipe and a cap with a hinge and lock was attached to the collar. The bottom of the enclosure was attached to an $11 \mathrm{~kg}$ weight and foam floats were attached to the top to ensure the enclosure and array would remain in a vertical orientation. A braided rope was threaded through a hole at the bottom of the PVC pipe and through a hole near the top, in order to assist deployment and removal.

Programming and data downloading for each ITD unit is done using a personal computer, a Dual Blue Dot receptor with USB connectivity, and OneWireViewer software. The Dual Blue Dot receptor can be purchased from Maxim Integrated Products and the OneWireViewer can be downloaded for free from the company's website. Every ITD unit has a unique serial number and this number is used to map each ITD to its location on the thermal array. For the evaluation study (see Section 6.3), all twenty ITD units (spaced $10 \mathrm{~cm}$ apart) were synchronized to take temperature readings at the same time at $30 \mathrm{~min}$ intervals. This configuration was used to measure a vertical temperature profile in a wet detention pond as a function of time.

\subsection{Evaluation Study}

From September 9 to October 16, 2009 a thermal array (as shown in Figure 6.2 above) was placed into a wet detention pond in Regina to evaluate the logistics of deploying the array and its ability to function in conditions found in the pond The detention pond that was used in the study (see Figure 
6.3) was about 2 ha area, had a permanent water depth of $2 \mathrm{~m}$, and serviced a catchment that was mostly residential with some retail development The thermal array was placed near the north inlet, as shown in Figure 6.3, which is a $600 \mathrm{~mm}$ pipe that rests on the pond bottom and projects into the pond approximately $14 \mathrm{~m}$ from the shoreline The array remained in place during the entire monitoring period and data was not downloaded until it was removed on October 16.

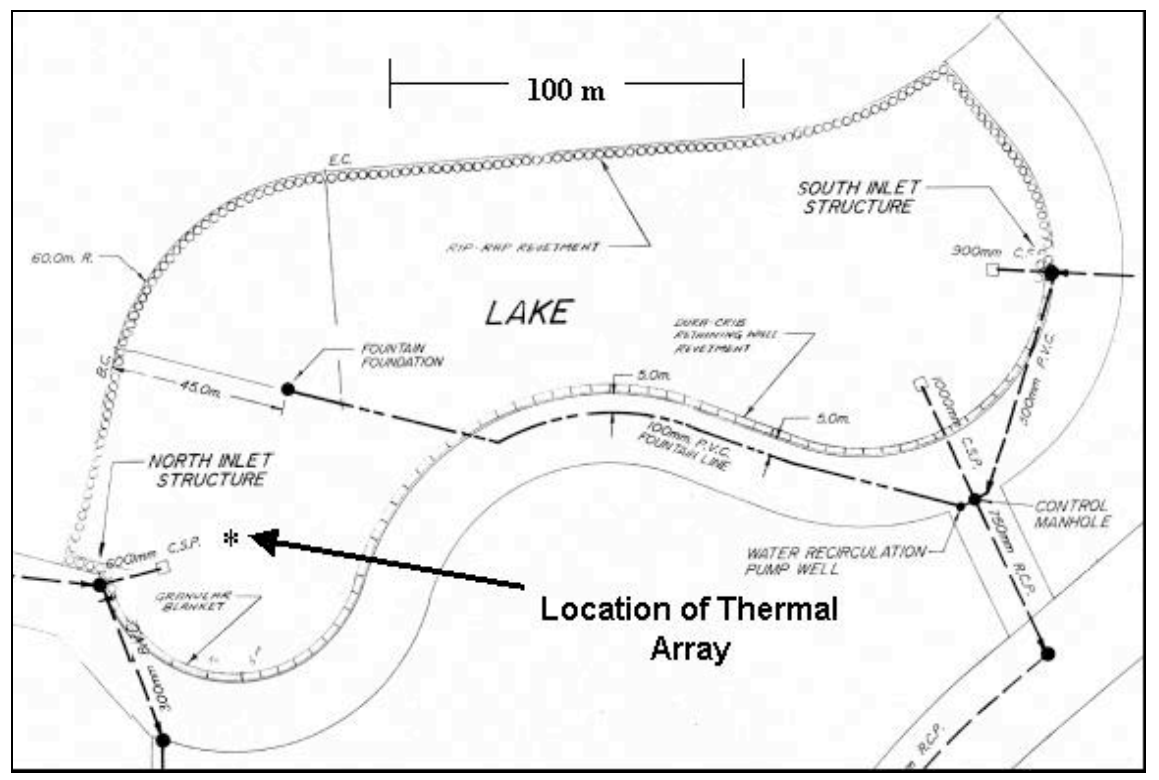

Figure 6.3 The wet detention pond, located in Regina, Saskatchewan, which was used in the evaluation study.

Shown in Figure 6.4 are temperature histories at the water surface, at $190 \mathrm{~cm}$ and $10 \mathrm{~cm}$ from the pond bottom and the water level in the pond, which were observed during the monitoring period. The surface temperature shows a diurnal pattern of the air temperature just above the pond surface, which was measured inside a piece of pipe insulation that floated on the water surface (see Figure 6.2 above). An attenuated diurnal pattern is also observed at $190 \mathrm{~cm}$ above the pond bottom, which is the nearest measurement below the water surface. As this evaluation study was conducted during the fall season, a drop in pond water temperature of about $12{ }^{\circ} \mathrm{C}$ to $16{ }^{\circ} \mathrm{C}$ (from beginning to end of the monitoring period) was observed, which was caused by declines in air temperature and incoming solar radiation. Between October 8 and October 12 there was ice formation on the pond 
surface, which disconnected the atmospheric pressure from the level logger and resulted in showing a drop in water level (no attempt to correct for this was made). For most of the observation period between September 9 and October 4, the temperature in the water column decreased from top to bottom (as seen in Figure 6.4). Around October 4 an inversion occurred and the temperature began to increase from top to bottom, in a manner similar to that observed in lakes in cold climate regions.

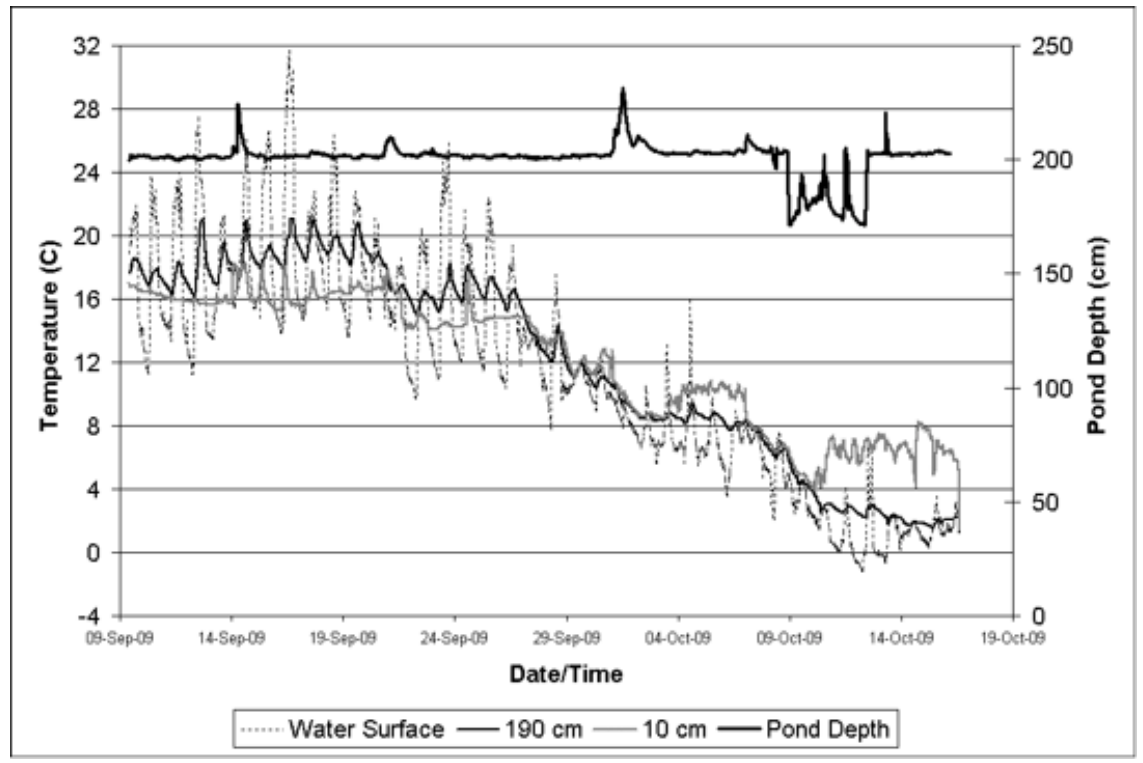

Figure 6.4 Temperatures above the water surface, $190 \mathrm{~cm}$ and $10 \mathrm{~cm}$ from pond bottom and the water level, at the monitoring location.

During rainfall events on September 14, September 21 and October 1, the vertical temperature gradient in the water column quickly disappeared, as runoff water entering the pond forced complete mixing of the water within the column. Temperature plots of the rainfall event that occurred on September 14 are shown in Figure 6.5. From 12:00 a.m. to 6:00 a.m., about $5 \mathrm{~mm}$ of rain fell on Regina, with most of this rainfall occurring between 5:30 a.m. and 6:00 a.m. (All precipitation, air temperature, and wind speed data were obtained from the Regina International Airport weather station operated by Environment Canada.) The runoff entering the wet detention pond caused the water level to rise, reaching a peak depth of about $23 \mathrm{~cm}$ above the normal water level. After the rainfall stopped, the temperature remained uniform in the water column because flow continued in the pond as it 
drained to its normal water level. Once the discharge from the pond ceased and the flow within the pond slowed, the vertical temperature gradient reappeared as the air and solar radiation began to heat the upper layers of the water column.

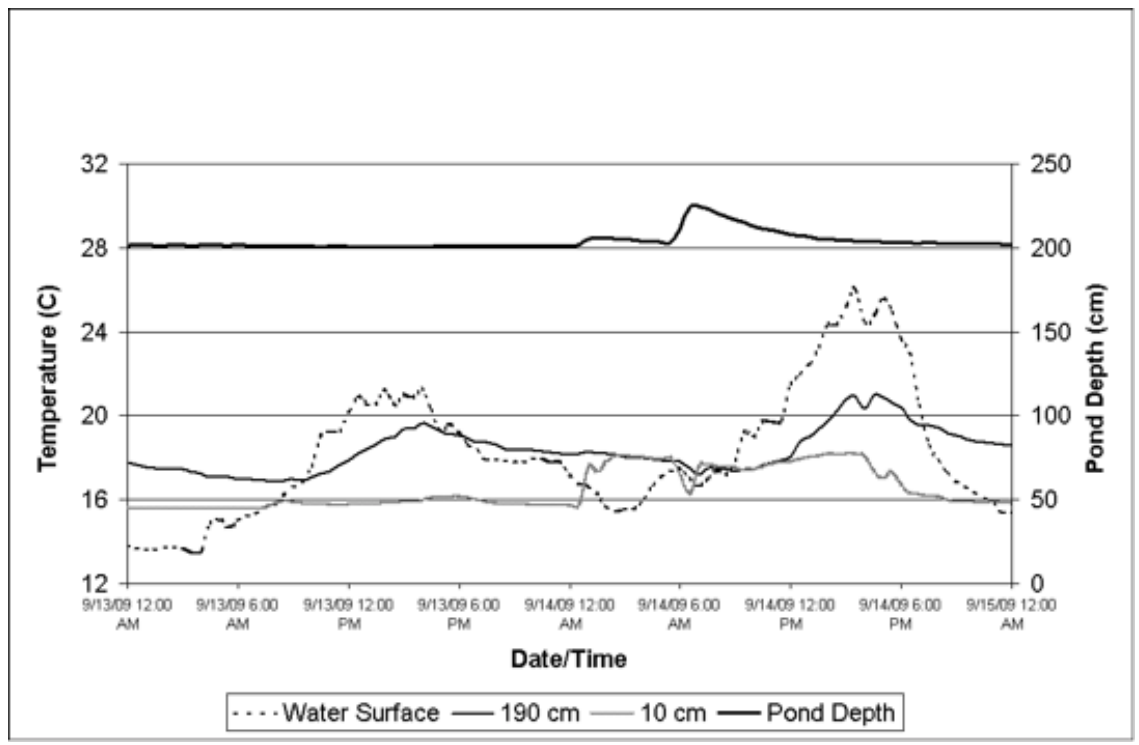

Figure 6.5 Vertical temperature profile for a 6-hour rainfall/runoff event on September 14, 2009.

Similar observations were found for the rainfall events on September 21 and October 1. A uniform vertical temperature profile during rainfall events suggests that a single temperature measurement anywhere within the water column can be used to represent the temperature of the water that is being discharged from the pond. However, the assumption of a uniform temperature throughout a pond during rainfall events should be confirmed with additional measurements near the outlet of the pond, and at other ponds. This is planned in future monitoring work.

During the period from 6:00 p.m. on September 26, 2009, to 6:00 a.m. on September 28, 2009, there was a significant cooling of air temperature accompanied by strong winds. The air temperature dropped from $16.5^{\circ} \mathrm{C}$ to $5.5^{\circ} \mathrm{C}$ and the average wind speed was $32 \mathrm{~km} / \mathrm{h}$ with gusts up to $74 \mathrm{~km} / \mathrm{h}$ The effects on the vertical temperature profile in the pond are shown in Figure 6.4 above. The water temperature dropped $2{ }^{\circ} \mathrm{C}$ to $4{ }^{\circ} \mathrm{C}$ over this time period with a temperature profile that had very little gradient in the vertical direction. This portion of the monitoring period shows the influence of the 
strong winds on keeping the pond water well mixed and at a uniform temperature.

An interesting and unexpected phenomenon that was observed during the monitoring period was a sharp temperature gradient between $40 \mathrm{~cm}$ and $50 \mathrm{~cm}$ from the pond bottom that was noticeably larger than any other temperature gradients in the vertical column, as shown in Figure 6.6. The average temperature change over a $10 \mathrm{~cm}$ interval was computed as the temperature at $190 \mathrm{~cm}$ minus the temperature at $10 \mathrm{~cm}$ all divided by 18 , for each time sample. The mean value of the magnitude for the average temperature change over a $10 \mathrm{~cm}$ interval, for the monitoring period, was $0.1^{\circ} \mathrm{C}$. The mean value of the magnitude for the temperature change between $40 \mathrm{~cm}$ and $50 \mathrm{~cm}$ was $1.0^{\circ} \mathrm{C}$, an order of magnitude greater than the average. This sharp temperature change suggests the presence of a thermocline between $40 \mathrm{~cm}$ and $50 \mathrm{~cm}$ during calm conditions; additional measurements at different locations in the pond would enable us to determine if this is a thermocline or some other phenomenon.

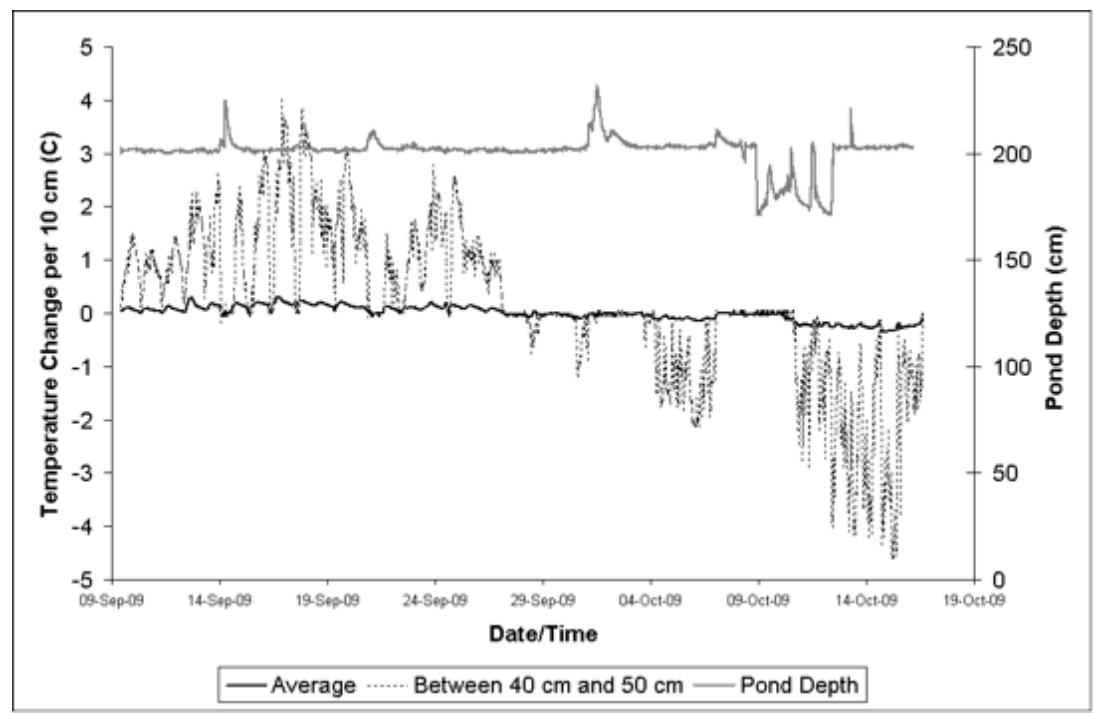

Figure 6.6 Temperature change over $10 \mathrm{~cm}$ intervals from the bottom to the top of water column during evaluation period.

As mentioned in Section 6.1, the primary purpose for developing this thermal array was to collect data to validate computer models that simulate the hydrothermal behaviour of stormwater ponds. For this evaluation study, local air temperature, humidity, wind velocity or solar radiation were not measured. These data are needed, along with the temperature measurements 
from the thermal array, to validate model simulations of the thermal energy balance in the pond. However, the temperature measurements from the thermal array can be used to examine the sensitivity of the distances between temperature measurements to the calculations for heat fluxes and stored thermal energy within the water column of the pond.

Such sensitivity analyses are useful because numerical models use temperatures at discrete points in the water column to compute values for these parameters. There is a tradeoff between the number of temperature points used in these computations and the speed of the simulation - the more points, the slower the simulation. There is also a tradeoff between the number of temperature points and the accuracy of the computations - in general, the more points, the more accuracy. To determine the optimal number of discrete temperature points (which will be denoted as nodes) and their locations, one needs to know the sensitivity of the spacing between the nodes to the accuracy in the calculations of these parameters.

Three configurations of temperature nodes will be used to examine the sensitivity of the vertical distance between temperature measurements to values for heat flux and internal energy within the water column. The three configurations are shown in Table 6.1 and were chosen so that the nodes were equally spaced and align with sensors in the thermal array.

Table 6.1 Locations of temperature measurements for the three node configurations.

\begin{tabular}{cccc}
\hline Elevation $(\mathrm{cm})$ & 19 nodes & 7 nodes & 3 nodes \\
\hline 190 & $\mathrm{X}$ & $\mathrm{X}$ & $\mathrm{X}$ \\
180 & $\mathrm{X}$ & & \\
170 & $\mathrm{X}$ & & \\
160 & $\mathrm{X}$ & $\mathrm{X}$ & \\
150 & $\mathrm{X}$ & & \\
140 & $\mathrm{X}$ & & \\
130 & $\mathrm{X}$ & $\mathrm{X}$ & \\
120 & $\mathrm{X}$ & & \\
110 & $\mathrm{X}$ & & \\
100 & $\mathrm{X}$ & $\mathrm{X}$ & \\
90 & $\mathrm{X}$ & & \\
80 & $\mathrm{X}$ & & \\
70 & $\mathrm{X}$ & $\mathrm{X}$ & \\
60 & $\mathrm{X}$ & & \\
50 & $\mathrm{X}$ & & \\
40 & $\mathrm{X}$ & $\mathrm{X}$ & \\
30 & $\mathrm{X}$ & & \\
20 & $\mathrm{X}$ & & \\
10 & $\mathrm{X}$ & $\mathrm{X}$ & $\mathrm{X}$ \\
\hline
\end{tabular}

Accurate values of the heat fluxes at the top and bottom of the water column are needed because they are important parameters in the heat balance 
between the atmosphere and water column and the pond bottom and water column, respectively. At the water surface, the heat flux boundary condition at the water surface can be expressed as:

$$
-\left.k \frac{\partial T}{\partial z}\right|_{S U R F}=q_{R A D}^{\prime \prime}-q_{E V A P}^{\prime \prime}-q_{C O N V}^{\prime \prime}-q_{A D V}^{\prime \prime}
$$

where

$$
\begin{aligned}
k & =\text { thermal conductivity of water, } \\
T & =\text { water temperature, } \\
z & =\text { elevation in the water column, } \\
q{ }_{R A D} & =\text { net radiation heat flux at the surface, } \\
q{ }^{\prime}{ }_{E A P} & =\text { heat flux due to evaporation from the water surface, } \\
q{ }_{C O N V} & =\text { heat flux due to air convection at the water surface, } \\
& \text { and } \\
q{ }_{A D V} & =\text { heat flux due to advection in the water column near } \\
& \text { the water surface. }
\end{aligned}
$$

The positive direction of heat movement is defined to be from the bottom to the top of the column.

The closest measurement to the water surface in the thermal array is at $190 \mathrm{~cm}$ from the pond bottom. Assuming a linear temperature profile between nodes, the heat flux boundary condition at the water surface can be estimated for the three configurations, as follows:

$$
-\left.k \frac{\partial T}{\partial z}\right|_{\text {SURF }} \cong-100 k \frac{T_{190}-T_{i}}{(190-i)} \quad i=\left\{\begin{array}{c}
180, \text { for } 19 \text { nodes } \\
160, \text { for } 7 \text { nodes } \\
100, \text { for } 3 \text { nodes }
\end{array}\right\}
$$

The index $i$ is the elevation from the pond bottom in centimetres, and the multiplier of 100 on the right-hand side of the relationship in Equation 6.2 is to keep the heat flux expressed in units of $\mathrm{W} / \mathrm{m}^{2} /{ }^{\circ} \mathrm{C}$. The approximated surface heat flux for the three configurations is shown in Figure 6.7, for the monitoring period. A value of $0.6 \mathrm{~W} / \mathrm{m}^{2} /{ }^{\circ} \mathrm{C}$ was used for the thermal conductivity $(k)$ of the water.

In Figure 6.7, a diurnal pattern is seen in the near-surface heat flux for all three configurations but the amplitudes of the heat flux oscillations diminish noticeably as the node spacing decreases from 19 to 3 nodes. These results indicate that the temperature profile near the water surface is nonlinear. This means that even if temperature predictions from computer simulations using 7 or 3 nodes match well with experimental data at those temperature points, using those temperature values to determine the near-surface conductive heat flux can result in an inaccurate approximation of the flux (compared to the 19-node configuration), depending on the time of day. One could use non- 
linear functions, such as second or third order polynomials, to approximate the temperature profile between the nodes but measurements between these nodes should also be taken to confirm the validity of using these functions.

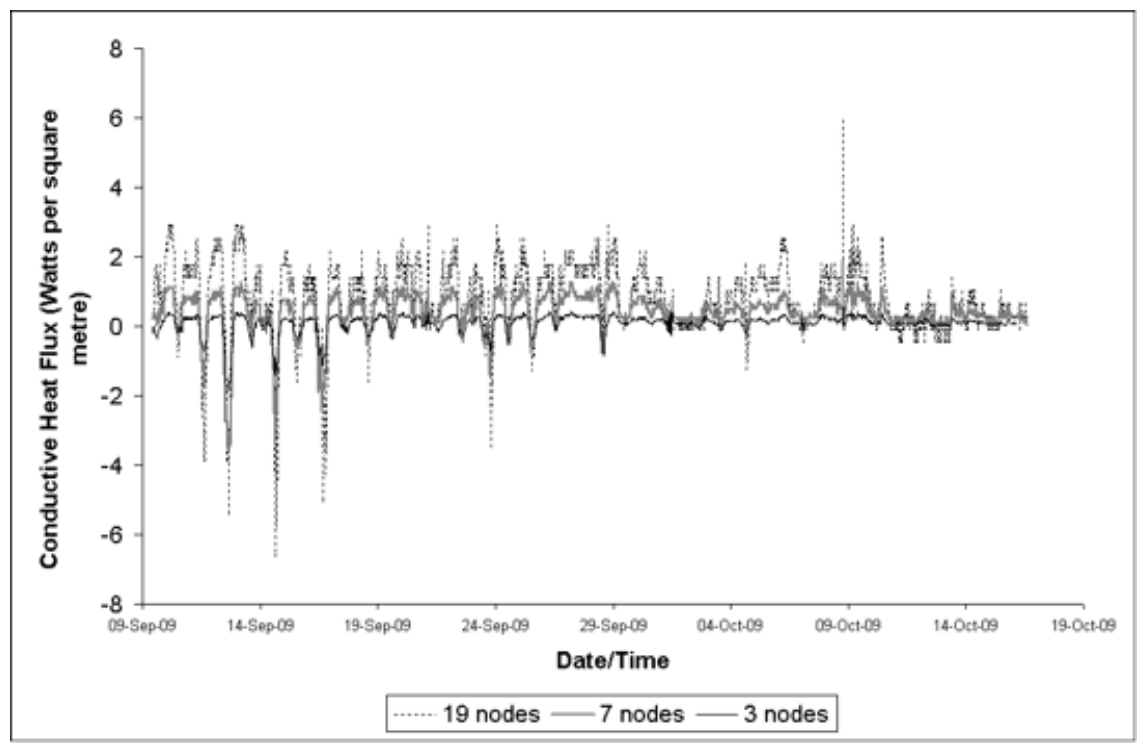

Figure 6.7 Conductive heat flux near the water surface calculated using Equation 6.2 for 19, 7 and 3 temperature nodes.

In Figure 6.8, the heat flux through elevation $180 \mathrm{~cm}$ is shown for the three configurations. Equation 6.2 is used but a value of $i=170$ is used for the 19-node configuration, instead of $i=180$. There is a much closer agreement between the 19-node and 7-node configurations. Moving down towards the middle of the water column, the temperature profile becomes linear and there is virtually no difference in the calculated conductive heat flux among the three configurations. In the bottom half of the water column, a similar pattern is seen in that near the boundary of the water and pond bed the temperature profile is nonlinear but becomes more linear towards the middle of the column. Based on these observations, a modified 7-node configuration with sensors at $190 \mathrm{~cm}, 180 \mathrm{~cm}, 160 \mathrm{~cm}, 100 \mathrm{~cm}, 40 \mathrm{~cm}, 20 \mathrm{~cm}$, and $10 \mathrm{~cm}$ would be a good configuration for the thermal array that balances the number of temperature points with accuracy in heat flux calculations. 


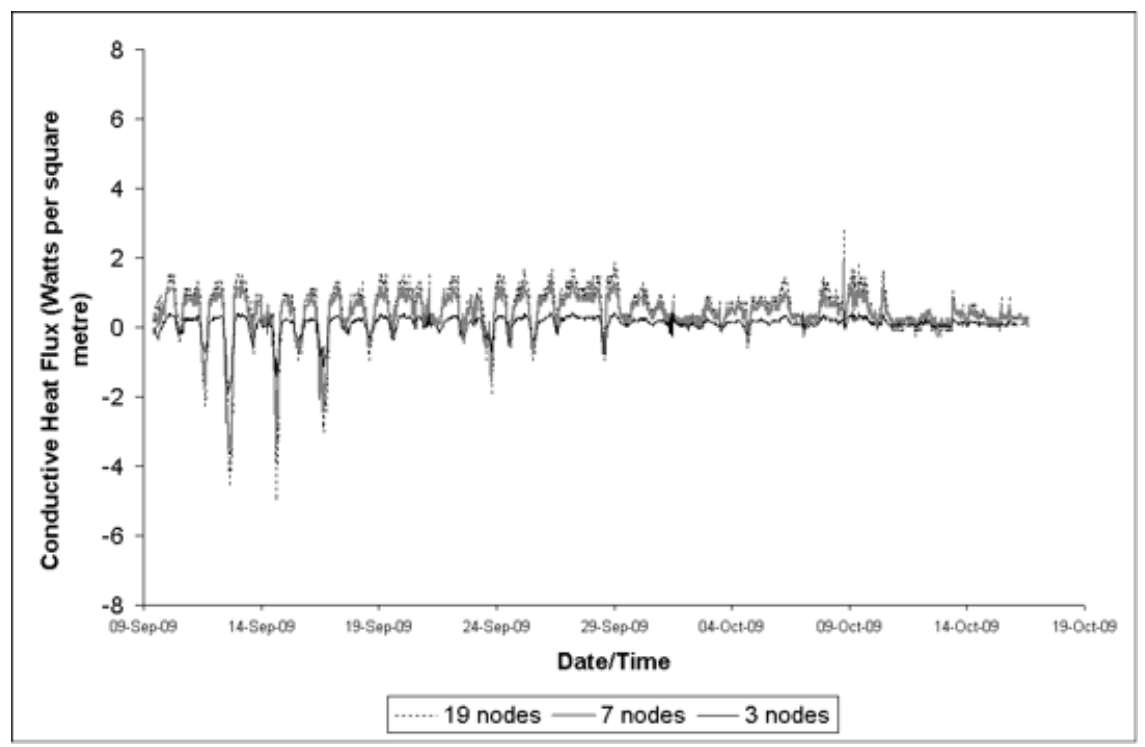

Figure 6.8 Conductive heat flux at $180 \mathrm{~cm}$ from the pond bottom for 19,7 and 3 temperature nodes.

The data from the thermal array can also be used to examine the sensitivity of temperature node configuration to the calculations for stored thermal energy within the water column of the pond. This parameter is a key component of the heat balance in the pond water, which is expressed as a one-dimensional differential equation, in the vertical direction, as:

$$
\frac{\partial}{\partial t}\left(\rho(T) c_{P}(T) T\right)=\frac{\partial}{\partial z}\left(-k \frac{\partial T}{\partial z}\right)+S
$$

The left-hand side of Equation 6.3 is the change in stored thermal energy, where $t$ is time, $T$ is temperature, $\rho(T)$ is the water density as a function of temperature, and $c_{P}(T)$ is specific heat capacity of water as a function of temperature. On the right-hand side of the equation, $z$ is elevation from the pond bottom, $k$ is the thermal conductivity of water, and $S$ is a heat source/sink term. For the range of conditions observed in the pond, pressure is assumed constant for evaluating density and specific heat capacity.

At any given time, the stored thermal energy in the water column can be estimated from the thermal array data using Equation 6.4:

$$
\text { Stored thermal energy }=\sum_{i=1}^{n} \rho\left(T_{i}\right) c_{P}\left(T_{i}\right) T_{i} \Delta z_{i}
$$


where

$$
\begin{aligned}
n= & \text { number of temperature nodes in the configuration } \\
& (\text { i.e. } 3,7, \text { or } 19) \text { and } \\
\Delta z_{i}= & \text { cell length for temperature node } i .
\end{aligned}
$$

In Figure 6.9, plots for the stored thermal energy are shown for the 19node, 7-node, 3-node, and the modified 7-node configurations. Values for water density and specific heat capacity were obtained from Haar et al. (1984), and the cell lengths are shown in Table 6.2 below. The plots in Figure 6.9 show that when compared to the 19-node configuration, the 7-node and 3-node configurations underestimate the amount of stored energy in the column; however, the modified 7-node configuration is a very good fit. This shows the importance of the spacing between temperature measurements near the water surface.

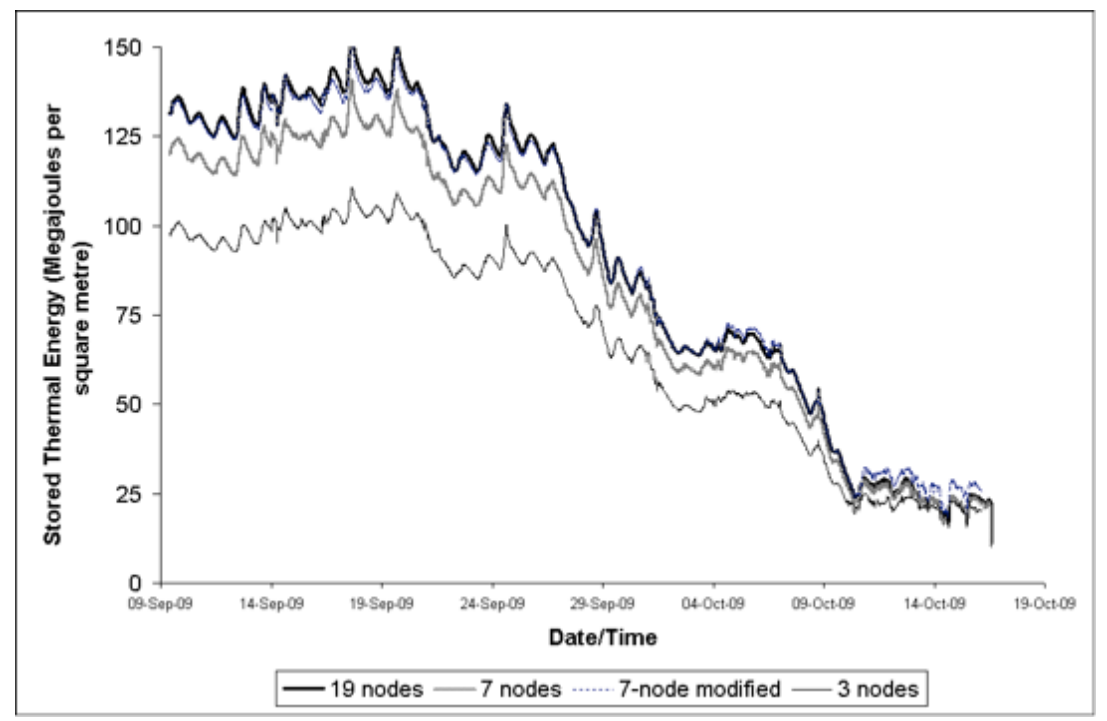

Figure 6.9 Stored thermal energy calculated for 19,7 and 3 temperature nodes and the modified 7 -node configuration.

In this section, the benefit of having a fine resolution of temperature measurements through a water column in a stormwater pond was shown. The arrangement of ITD units (as shown in Figure 6.2) for this evaluation study permitted evaluations of the sensitivity of distances between temperature measurements to the calculation of conductive heat fluxes and stored thermal energy in the water column. It also showed a noticeably larger temperature change occurring between $40 \mathrm{~cm}$ and $50 \mathrm{~cm}$ from the pond bottom compared to elsewhere in the water column. 
Table 6.2 Lengths of cell $\Delta z_{i}$ (in centimetres) for the temperature nodes.

\begin{tabular}{ccccc}
\hline Elevation $(\mathrm{cm})$ & 19 nodes & 7 nodes & 3 nodes & $\begin{array}{c}\text { Modified } \\
7 \text { nodes }\end{array}$ \\
\hline 190 & 5 & 15 & 45 & 5 \\
180 & 10 & & & 15 \\
170 & 10 & 30 & & 40 \\
160 & 10 & & & \\
150 & 10 & & & \\
140 & 10 & 30 & & \\
130 & 10 & & & \\
120 & 10 & 30 & & \\
110 & 10 & & & \\
100 & 10 & 30 & & \\
90 & 10 & & & \\
80 & 10 & & & \\
70 & 10 & 30 & & \\
60 & 10 & & & \\
50 & 10 & 30 & \\
40 & 10 & 30 & & \\
30 & 10 & & & \\
20 & 10 & & & \\
10 & 5 & 15 & & \\
\end{tabular}

\subsection{Summary}

In this chapter, a thermal sensor array was described that measures the vertical temperature profile in a wet detention pond. A key objective in the development of this array was to minimize cost while maintaining highquality data collection, so that several arrays could be deployed at a reasonable expense. It was decided to use the iButton technology for the thermal array prototype.

The array that is described in Section 6.2 was placed into a wet detention pond in Regina from September 9, 2009, to October 16, 2009. The array performed as expected and data from it permitted study of the sensitivity of distances between temperature measurements to the calculation of conductive heat fluxes and stored thermal energy in the water column. These sensitivity studies revealed that a finer resolution of temperature measurements near the boundaries of the water surface and the pond bottom are needed compared to the middle of the water column. This information is not only useful for future monitoring projects but also for computer simulations, in terms of helping to establish the optimal number of computation points for temperatures in the water column.

Although the iButton ITD units performed as expected, for future monitoring projects the Tidbit ITD units likely will be used because data can be 
downloaded from them without having to remove the units from the array, using a waterproof shuttle instead of a laptop computer. This capability will save time during the downloading of data and this timesaving is believed to be worth the extra cost of the sensors.

\section{Acknowledgments}

The National Research Council of Canada funded this work through the Institute for Research in Construction's Urban Infrastructure (UI) Program, at the Centre for Sustainable Infrastructure Research (CSIR) in Regina, Saskatchewan. The authors would like to Ms Kerri Webb (Water Resources Technology student from the Saskatchewan Institute of Applied Science and Technology) for her help in preparing and installing the thermal array, Mr. Joseph Alejandria (City of Regina) for providing drawings for the wet detention pond that was used in the evaluation study, and Dr Yafei Hu and Dr Imran Syed for their helpful comments.

\section{References}

Galli, J., Thermal impacts associated with urbanization and stormwater best management practices, Metropolitan Washington Council of Governments, Washington, D.C. 1990.

Haar, L., Gallagher, J., and Kell, G., NBS/NRC Steam Tables: Thermodynamic and Transport Properties and Computer Programs for Vapor and Liquid States of Water in SI Units, Taylor and Francis Publishers, 1984.

Herb, W.R., Mosheni, O., and Stefan, H.G., Simulation of temperature mitigation by a stormwater detention pond, Journal of the American Water Resources Association, Vol. 45(5), 2009.

James, W. and Xie, J.D.M. , Storm water heating of urban streams, Proceedings of the Annual Conference of the Canadian Society of Civil Engineers, Regina, Saskatchewan, June 2-5, pp 569-578, 1999.

Kieser, M.S., Spoelstra, J.A., Fang, A.F., James, W. and Li, Y., Stormwater thermal enrichment in urban watersheds, Water Environment Research Foundation (WERF) Report 00-WSM-7UR, IWA Publishing, London, 2004.

Li, Y. and W. James. 2004. "Thermal Enrichment by Stormwater: Application to an Urban Area with Shopping Mall and Treatment Wetland." Journal of Water Management Modeling R220-32. doi: 10.14796/JWMM.R220-32.

Maxim Integrated Products, website: http://www.maximic.com/products/ibutton/software/1wire/OneWireViewer.cfm\#installing

Nelson, K.C. and M.A. Palmer, Stream temperature surges under urbanization and climate change: data, models, and responses, Journal of the American Water Resources Association, Vol. 43(2), 440-452, 2007.

Ontario Ministry of the Environment, Stormwater management planning and design manual, Queen's Printer for Ontario, ISBN 0-7794-2969-9, 2003. 
Shaw, J., Watt, W., Marsalek, J., Anderson, B., and Crowder, A., Flow pattern characterization in an urban stormwater detention pond and its implications for water quality, Water Quality Research Journal of Canada, Vol. 32(1), pp 53-71, 1997.

Thomann and Mueller, Principles of Surface Water Quality Modeling and Control, Harper Collins Publishers, New York, 1987.

Van Buren, M.A.V., Thermal enrichment of urban receiving waters, Ph.D. Thesis, Queens University, Kingston, Ontario, Canada, 1999.

Verspagen, B., Experimental investigation of thermal enrichment of stormwater runoff from two paving surfaces, Masters Thesis, University of Guelph, Guelph, Ontario, Canada, 1995. 
